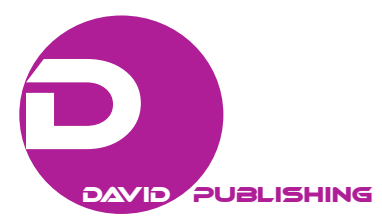

\title{
Reading the Visual Design of Job Advertisements in Taiwanese Newspapers
}

\author{
Chin-Hui Chen, Shu-Wen Chuang \\ National Pingtung University of Science and Technology, Pingtung, Taiwan
}

\begin{abstract}
This content analysis of print advertisements for jobs focuses on changes in choices of visual semiotic resources over time. Recruitment advertisements as a genre of persuasion discourse require careful design, not only in terms of writing but also in the selection of visual images, which can help attract candidates' attention and therefore enhance the effectiveness of the messages conveyed. It has also been argued that changes in visual-communication styles of recruitment advertisements could, to some extent, reflect how such advertisements were perceived as functioning from the employers' perspectives. In this paper, content analysis of job advertisements as printed in weekend newspapers in three different years (1993, 2003, and 2013) revealed that: (1) the presence of visual content in job advertisements fluctuated over the past two decades; and (2) to make recruitment advertisements more eye-catching, visual images were more likely to be placed in areas identified as salient in theoretical terms. The results shed new light on the roles played by the visual semiotic resources of job advertisements for the purpose of attracting human resources effectively.
\end{abstract}

Keywords: recruitment advertisements, content analysis, visual communication, newspapers, Taiwan

\section{Introduction}

\section{Recruitment and Job Advertisements}

Print-media recruitment advertising, part of a wider genre known as "want ads", is one of the central operations used when drawing potential human resources into a company. Recruitment has always been regarded strategically important to the success of a company, and hence has received considerable academic attention in the field of management (for a review, see Breaugh \& Starke, 2000). Recruitment advertising, historically the most commonly used tool for approaching potential employees (Martin, 1987), has also been widely discussed in terms of its effectiveness and impact (Blackman, 2006; Kaplan, Aamodt, \& Wilk, 1991; Mathews \& Redman, 2001; Roberson, Collins \& Oreg, 2005). Literature on the communicative effectiveness of job advertisements has also emerged from the field of marketing (Rai \& Kothari, 2008; Ryan, Gubern, \& Rodriguez, 2000). Much as commercial messages in advertisements promote a product to customers, recruitment advertisements target job-seekers. As indicated by Ryan et al. (2000), recruitment advertising, as perceived from a marketing viewpoint, sells jobs as products by means of certain mechanisms that are intended to motivate their customers (job seekers) to fulfill an organizational goal: that is, to sustain the business with quality human resource input.

Chin-Hui Chen, Ph.D., Assistant Professor, Department of Modern Languages, National Pingtung University of Science and Technology.

Shu-Wen Chuang, Postgraduate Student, Department of Modern Languages, National Pingtung University of Science and Technology. 
Adopting this perspective, the present research examines job advertisements as a form of business and marketing communication, in which context the design of such messages becomes a topic worthy of discussion.

\section{Analyzing the Appeal of Job Advertisements in Newspapers}

Newspapers have traditionally been a usual medium in which recruiters advertise information about job vacancies (Fyock, 1988; Greenberg, 1986). The benefits of the use of newspapers for this purpose include spatial flexibility: i.e., a job advertisement can be as small as a classified ad, or as large as a full page (Kaplan et al., 1991). It is also effective to reach a large pool of applicants through newspapers (Davids, 1986). Recruitment advertisements, as a public discourse, can also construct corporate images when it is read by audiences other than just active job-seekers (Stoops, 1984). Given that recruitment advertisements in newspapers can be costly (as opposed to free or relatively low cost ones in new media alternatives), its effectiveness is a question worth exploring.

Rawlinson (1988) suggested that the inclusion of sufficient space as well as large and eye-catching titles can help one job advertisement stand out among many others. Kaplan et al. (1991) examined applicants' responses to job advertisements, and reported that in addition to size, physical characteristics such as the proportion of white space, borders and graphics were positively related to increases in applicant pools. Allen, Mahto, and Otondo (2007) similarly found that recruitment messages that included visual elements such as graphics, or colorful images were more effective for conveying information. However, Magnus (1986) also argued that merely including graphics or art work was not sufficient to make a job advertisement creative and distinctive. Other researchers have stressed that company images presented in a positive manner (Magnus, 1986; Rawlinson, 1988) can significantly affect potential candidates' decisions to apply for positions (Belt \& Paolillo, 1982). Visual communication hence plays a role in the design of effective job advertisements.

In terms of the content, a subgenre of job ads that can be termed company-centered generally include components such as an institutional name/website, position information, expected candidate qualifications, application requirements and contact details, and equal opportunity statements (Cook, 2002). Cook (2002) also advised that candidate-centered job announcements, in contrast, should be produced to target the audience members in terms of what they want: i.e., be designed in light of a candidate's probable perspective, provide realistic job previews, help candidates see themselves in the organization, and attract candidates with vivid language harnessed to the provision of personally relevant messages.

Other studies (e.g., Huang, Chang, \& Du, 2002; Kaplan et al., 1991) have discussed recruitment advertisements from the perspective of human resource management, but rarely via any systematic analysis of the theoretical rationales behind either their textual or visual design. Although this paper is also concerned with how the design of job advertisements can efficiently draw job applicants' attention, we are particularly interested in exploring the visual communication mechanism, how it achieves saliency and what can be inferred from changes in visual design over time. To answer such questions, we draw on a theory introduced by two linguists, Gunther Kress and Theo van Leeuwen, whose research is based on multimodal analysis and focused on the grammar of image design as well as the meanings.

\section{Literature Review}

\section{Visual Communication and the Grammar of Images}

The use of visual images for communication, from a meaning-making perspective, can be seen as an aid to 
or a substitute for language (Fairclough, 2001). For instance, a sign featuring a smile can represent the notion of happiness. It has been argued that using visual content to communicate in a job advertisement can make conveying messages more effective, as pictures are powerful means of making readers remember content (Lester, 2014).

In the process of visual communication, the interactions between those involved need to be taken into account even when there is no face-to-face contact. In the specific context of recruitment advertisements, the employer plays the role of image producer, while job applicants operate as decoders of meanings in the images. According to Kress and van Leeuwen (2006), interactions via images can hence be categorized into two types: the first being between participants represented in the images, and the second, between interactive participants (e.g., employers vs. candidates), activated by understanding of the meaning-potential in the images. As stated by Kress and van Leeuwen (2006, p. 2), "like linguistic structures, visual structures point to particular interpretations of experiences and forms of social interactions". Accordingly, the present study investigates visual structures as components of job advertisements, and draws inferences about the kinds of interactions between employers and the targeted job applicants that are endorsed by the job advertisements under study.

In order to analyze the images in job advertisements, this paper employs Kress and van Leeuwen's (2006) theories on grammar of images. Kress and van Leeuwen's (2006) grammar of images can be discussed in terms of a number of dimensions, such as placement and salience.

Placement of images can be defined as the spatial composition of images. The composition of the elements (e.g., images, words, or frame) would give them different information values. Placing images on the left (given) and right (new), top (ideal) and bottom (real), or the central and marginal area has different values and effects (Kress \& Van Leeuwen, 2006).

The left-hand side is endowed with given information and the right-hand side with new information. Given information means that something viewers are assumed to know or something they are familiar with. New information means that presenting something which is not yet known, or something that readers should pay attention to.

As for top and bottom, the former represents the ideal and the latter the actual. The upper area shows us what might be and the lower area shows us what it is. As to the contrast between the center and the margins, the composition of the center represents the nucleus of the information while the marginal elements are subservient to those in the central area (Kress \& Van Leeuwen, 2006). Hence, it is assumed that the information in the center is endowed with greater information values than that in the margins. Kress and Van Leeuwen (2006) also stated that the upper area is more salient than the lower area. As a result, it is assumed that rightward and top visual content may draw individuals' attention to a greater extent.

As discussed earlier, a recruitment advertisement can be designed as either company-centered or candidate-centered in nature. The latter blends the idea of job advertisements as a form of marketing or promotional discourse with messages that are designed to appeal to the addressees, namely, the job applicants. As such, its rhetoric is intended to evoke responses from the readers' mind, and also an indirect interaction. The above two communicative orientations could also be reflected in the visual content of a job advertisement. Alongside the question of company vs. candidate orientation, it is worth exploring whether company-oriented and candidate-oriented images treated differently with regard to their placement and salience in these advertisements.

In light of the above discussion, we ask the following research questions: 
RQ1: How frequently were visual images present in Taiwanese newspaper recruitment advertisements in 1993, 2003, and 2013?

RQ2: In what ways did these images reflect a company-oriented or candidate-oriented perspective?

RQ3: How were the various images placed in these advertisements?

RQ4: Were company-oriented and candidate-oriented images treated differently with regard to their placement and salience in these advertisements?

\section{Methodology}

\section{Content Analysis of Recruitment Advertisements}

Content analysis, as a tool of text and discourse analysis (Titscher, Meyer, Wodak, \& Vetter, 2000), is characterized as objective, systematic and quantitative (Berelson, 1952; Holsti, 1969). This makes it suitable for studies such as ours, which attempt to uncover visual communication patterns in job advertisements by quantifying the features under study into distributional figures. Content analyses are often conducted for hypothesis testing, using statistical analysis based on the generated coding results under the guidance of a pre-determined manual. The operational procedures include sampling, coding, reliability testing, and statistical analysis.

The samples used in the content analysis in the present study were weekend job ads printed in the China Times, the United Daily News and the Liberty Times in 1993, 2003, and 2013. These long collection intervals were chosen in an attempt to discern long-term visual changes in the recruiting information shown in job ads, while the three particular newspapers were chosen as being the most widely read in Taiwan, according to a survey by Chang and Fu (2003). Weekend editions were chosen because more job ads tend to appear at weekends in Taiwan. As to the sampling mechanism, all the job ads printed during one randomly chosen weekend of each month in the targeted sampling years (1993, 2003, and 2013) were collected. This yielded 1,556 job ads for analysis, of which $47.6 \%(N=740)$ were from $1993,33.2 \%(N=517)$ from 2003 , and $19.2 \%$ $(N=299)$ from 2013.

The operational definitions of each dimension were explained as follows:

(1) Year. Job ads from 1993 were coded as"1", those from 2003 as "2", and those from 2013 as "3".

Presence of images. In the first stage of analysis, each ad that presented at least one image was coded as " 1 ", and those with no images as " 2 ".

(2) Placement of images. This can be divided into two parts, with the first part being upper or lower placement. Four code categories were created for this part: "1" = upper, "2" = lower, "3" = full-height, and "4" $=$ other (e.g., centered vertically). Secondly, left/right placement was again coded using four categories: "1" = left, " 2 " = right, " 3 " = full-height, and " 4 " = other (e.g., centered horizontally).

(3) Salience of images. This includes categories such as foregrounded (“1”) vs. backgrounded ("2").

(4) Image types. Based on previous research on recruiting information (Huang, Chang, \& Du, 2002), the present study, classified images as " 1 " if they were company-oriented (i.e., showing factories or other buildings, products, or working environments such as labs, offices, or production lines), and " 2 " if they were candidate-oriented (i.e., of human beings assumed to be the kinds of candidates the company desired). Images that fit neither of the above orientations, such as animals, cartoons, the Earth and so forth, were coded as" 3 ".

(5) Two coders were recruited to conduct the coding according to the above operational definitions. The intercoder reliability between the two coders was adequate, in that Krippendorff's alpha was greater than 0.8 (Krippendorff, 2004). 


\section{Results}

\section{The Presence of Images in Recruitment Advertisements}

As shown in Table 1, the degree to which images were present in the collected job ads varied considerably across the targeted years: rising from 9\% in 1993 to 64\% in 2003 and then decreasing dramatically back to 9\% in 2013 even though the numbers of the sampled job advertisements decreased over the two decades (from $47.6 \%$ to $19.2 \%$ ). In all, 426 job ads presented at least one image, but because some ads presented more than one, a total of 575 distinct images were identified. The apparent rise and fall of the use of visual images in recruitment ads over the 20-year period we studied may reflect major changes in the strategies that underlay the design of such ads, and/or changes in the foci of recruiting activities themselves. In 2003, companies seemed to pay more attention to visual communication in the design of job ads as a means to attract their potential job applicants.

Table 1

\begin{tabular}{llll}
\multicolumn{1}{l}{ Numbers of Job Ads With Images by Year } & & \\
\hline Year & Ads with images & Ads without images & Total \\
\hline 1993 & & & \\
$\quad$ Frequency & 66 & 674 & 740 \\
$\quad$ Within-year\% & $9 \%$ & $91 \%$ & $100 \%$ \\
2003 & & & \\
$\quad$ Frequency & 333 & 184 & 517 \\
$\quad$ Within-year\% & $64 \%$ & $36 \%$ & $100 \%$ \\
2013 & & & \\
Frequency & 27 & 272 & 299 \\
$\quad$ Within-year\% & $9 \%$ & $91 \%$ & $100 \%$ \\
Total & & & \\
$\quad$ Frequency & 426 & 1,130 & 1,556 \\
$\quad$ Within-total\% & $27 \%$ & $73 \%$ & $100 \%$ \\
\hline
\end{tabular}

\section{Image Types: Company-oriented or Candidate-oriented}

As previously mentioned, all images were identified as company-oriented, candidate-oriented or neither. Company-oriented images presented visual messages regarding company products, buildings, production lines, or offices to help job seekers get basic information about what the company is in terms of the above-mentioned facts. Candidate-oriented images, on the other hand, showed models who by implication had certain attributes that the targeted job applicants shared. In some cases, the models were portrayed performing specific actions that could also serve to define what the ideal candidates should be like.

Table 2 presents the relationships between image types and year of ads. Generally, company-oriented images $(N=295)$ were more prevalent than candidate-oriented ones $(N=112)$, which were also less common that other types of images $(N=168)$ in the sampled job ads. As can be seen in Table 2, approximately half of the images in 1993 and 2013 were in the "other" category. This contrasted sharply with 2003, when company-oriented images made up well over half of the total images found (56\%). To some extent, these changes might reveal that recruiters in 2003 were engaged in a strategic attempt to communicate messages about their companies' characteristics to potential candidates, beyond what the non-visual information alone could convey. 
Table 2

Frequency of Imagesby Type and Year

\begin{tabular}{lllll}
\hline Type/Year & 1993 & 2003 & 2013 & Total \\
\hline Company-oriented & & & & \\
$\quad$ Frequency & 21 & 269 & 5 & 295 \\
$\quad$ Within-year\% & $27 \%$ & $56 \%$ & $26 \%$ & $51 \%$ \\
Candidate-oriented & & & & \\
$\quad$ Frequency & 19 & 89 & 4 & 112 \\
$\quad$ Within-year\% & $25 \%$ & $19 \%$ & & $19 \%$ \\
Other & & 121 & 10 & 168 \\
$\quad$ Frequency & 37 & $25 \%$ & $53 \%$ & $29 \%$ \\
$\quad$ Within-year\% & $48 \%$ & 479 & 19 & 575 \\
Total & & $83 \%$ & $4 \%$ & $100 \%$ \\
$\quad$ Frequency & 77 & $13 \%$ & &
\end{tabular}

\section{Placement and Salience of Images in Job Advertisements}

Presence of full-height images. As shown in Table 3, a total of 41 full-height images were found in the data from all years, of which the overwhelming majority (83\%) were found in 2003. Full-height images were six times more prevalent in the 1993 data than in the 2013 data. However, the percentage of the total image sample made up by full-height images in each year was roughly comparable, i.e., 7.7\% (6 out of 77) in 1993, $7.0 \%$ (34 out of 479) in 2003 and 5.2\% (1 out of 19) in 2013, and the mean presence of such images was $7.1 \%$. The relative lack of interest in full-height images on the part of recruiters may reflect a feeling that it is inefficient to spend a large sum of money on highlighting just one visual image in a job advertisement, and that multimodal messages were seen as preferable by Taiwanese companies.

Table 3

Frequency of Full-Height Images in Job Advertisements by Year

\begin{tabular}{lllll}
\hline Placement & 1993 & 2003 & 2013 & Total \\
\hline Full heightimages & & & & \\
Frequency & 6 & 34 & 1 & 41 \\
$\%$ & $14.6 \%$ & $83 \%$ & $2.4 \%$ & $100 \%$ \\
\hline
\end{tabular}

Table 4

Frequency of Upper/Lower Placement of Images in Job Advertisements by Year

\begin{tabular}{lllll}
\hline Placement & 1993 & 2003 & 2013 & Total \\
\hline Upper & & & & \\
$\quad$ Frequency & 39 & 280 & 13 & 332 \\
$\quad$ Within-year\% & $55 \%$ & $73 \%$ & $72 \%$ & $70 \%$ \\
Lower & & & \\
$\quad$ Frequency & 32 & 103 & $28 \%$ & 140 \\
$\quad$ Within-year\% & $45 \%$ & 383 & 18 & $30 \%$ \\
Total & & & & 472 \\
$\quad$ Frequency & 71 & 383 & & \\
\hline
\end{tabular}

Presence of images in upper or lower areas. Table 4 indicates the relative frequency of images placed in the upper as opposed to the lower area of job ads. The results show that images classified as having upper 
placement were more prevalent than those with lower placement in all three of the targeted years: by nearly triple, in the case of ads from 2003 (73\% upper) and 2013 (72\% upper), while in the 1993 data, the two types were much more evenly split (55\% upper). These results may suggest a growing awareness, over the period 1993-2003, that upper placement was more eye-catching than lower placement. When visual messages were included in job advertisements in Taiwanese newspapers, they were more likely to be treated as ideal rather than reality, given Kress and van Leeuwen's visual theory (2006).

Presence of images in the left and right areas. Our analysis of the left or right placement of images is rooted in prior literature (Kress \& Van Leeuwen, 2006). Table 5 sets forth the comparison of the numbers of images placed in the right as opposed to in the left area. The results indicate that over the targeted three years, no great difference could be observed. In 1993, the percentage of left and right placements was the same (50\%). Ten years later, the proportion of images with right placement had grown to 54\%; and in 2013, this had decreased slightly to $46 \%$. Given Kress and van Leeuwen's theory, the results could be interpreted as that when Taiwanese companies included visual content, they did not just emphasize new but also information that the job applicants were familiar with. What comes next is the examination of image types (company-orientation and candidate-orientation) in relation to placement and salience so as to extend the discussion in this section.

Table 5

Frequency of Left/Right Placement of Images in Job Advertisements by Year

\begin{tabular}{lllll}
\hline Placement & 1993 & 2003 & 2013 & Total \\
\hline Left & & & & \\
$\quad$ Frequency & 19 & 126 & 7 & 152 \\
$\quad$ Within-year\% & $50 \%$ & $46 \%$ & $54 \%$ & $47 \%$ \\
$\begin{array}{l}\text { Right } \\
\quad \text { Frequency }\end{array}$ & 19 & 147 & 6 & 172 \\
$\quad$ Within-year\% & $50 \%$ & $54 \%$ & $46 \%$ & $53 \%$ \\
Total & & & \\
$\quad$ Frequency & 38 & 273 & 13 & 324 \\
\hline
\end{tabular}

Placement, Salience and Types of Images in Job Advertisements

Image types versus left and right placement. Table 6 reveals the relationship between the left-right placement of images, on the one hand, and image types, on the other hand. Given Table 6, in company-oriented images categorized in terms of left and right placement $(N=251)$, those placed on the left $(N=135,54 \%)$ were more than those on the right $(N=116,46 \%)$. A different pattern was found in the case of candidate-oriented images. Slightly more candidate-oriented images were placed on the right $(N=46,53 \%)$ than on the left $(N=40,47 \%)$. The results means Taiwanese companies regarded company-related facts or information as given while visual messages designed to define their targets were meant to be new to the readers.

Image types versusupper and lower placement. As can be seen from Table 7, among company-oriented images, those placed in the upper area $(N=177)$ outnumbered those in the lower area $(N=71)$ of the sampled job ads. A similar pattern could also be found in customer-oriented images. It seems that both image types were more likely positioned as ideal rather than reality (since more frequently in the upper rather than in the lower area) by Taiwanese companies in the process of designing visual communication in job advertisements. 
Types of images being foregrounded and backgrounded. To further understand the extent to which company-oriented and candidate-oriented images tended to be salient, we observed whether they were foregrounded or backgrounded in the sampled job advertisements. According to the visual grammar theory introduced by Kress and Van Leeuwen (2006), foregrounded placement is more salient than backgrounded placement.

Table 6

Types of Images Placed on the Left and Right of Job Ads

\begin{tabular}{llll}
\hline Image types & Left & Right & Total \\
\hline Company-oriented & & & \\
$\quad$ Frequency & 135 & 116 & 251 \\
$\quad$ Within-type\% & $54 \%$ & $46 \%$ & $100 \%$ \\
Candidate-oriented & & & \\
$\quad$ Frequency & 40 & 46 & 86 \\
$\quad$ Within-type\% & $47 \%$ & $53 \%$ & $100 \%$ \\
Total & & & 337 \\
$\quad$ Frequency & 175 & 162 & \\
\hline
\end{tabular}

Table 7

Types of Images Placed in the Upper and Lower Areas of Job Ads

\begin{tabular}{llll}
\hline Image types & Upper & Lower & Total \\
\hline Company-oriented & & & \\
Frequency & 177 & 71 & 248 \\
$\quad$ Within-type $\%$ & $71 \%$ & $29 \%$ & $100 \%$ \\
Candidate-oriented & & 31 & \\
$\quad$ Frequency & 66 & $32 \%$ & 97 \\
$\quad$ Within-type $\%$ & $68 \%$ & & $100 \%$ \\
Total & & 102 & 345 \\
$\quad$ Frequency & 243 &
\end{tabular}

Table 8

Frequency of Foregrounded and Backgrounded Images by Image Type

\begin{tabular}{llll}
\hline Image types & Foregrounded & Backgrounded & Total \\
\hline Company-oriented & & & \\
$\quad$ Frequency & 165 & 130 & 295 \\
$\quad$ Within-type $\%$ & $56 \%$ & $44 \%$ & $100 \%$ \\
Candidate-oriented & & & \\
$\quad$ Frequency & 72 & 40 & 112 \\
$\quad$ Within-type\% & $64 \%$ & $36 \%$ & $100 \%$ \\
Total & & 170 & 407 \\
$\quad$ Frequency & 237 & 170 & \\
\hline
\end{tabular}

Table 8 shows that more than half (56\%) of the company-oriented images were foregrounded. Among candidate-oriented images, the majority of them (64\%) were foregrounded as well. Both types of images were more likely displayed as foregrounded messages in job advertisements. That means when Taiwanese companies included visual messages in job advertisements which were more frequently textual, they would like to emphasize them and made them and make them easily noted by the readers. 


\section{Conclusion}

In sum, visual communication as observed in job advertisements in Taiwanese newspapers showed marked variations over time. Of the three sampled years, each a decade apart, 2003 saw the great majority of reliance on visual communication to attract candidates. The possible reasons for such a spike might be, firstly, long-term changes in the channels whereby job candidates look for information about job vacancies, and secondly, changes in employers' perceptions regarding how job advertisements ought to function. Specifically, people long tended to perceive classified advertisements as consisting of only a small amount of space and as containing a limited amount of textual information, e.g., a company's name, available job titles and contact details. This perhaps explains the pattern identified in 1993, when job advertisements were still the main tool for disseminating job information, and the competition for limited space in newspapers could be costly. Therefore, it seems likely that inclusion of visual content in 1993 was restricted due to high demand for advertising space and the resultant higher costs of such space. In 2003, in contrast, visual content played a dramatic, essential role in the design of job advertisements, with the majority including it. Moreover, the visual images sampled in that year were more likely to be placed in areas with greater value of saliency. This suggests that the employment of visual images in job advertisements was not a random decision.

Fewer candidate-oriented messages than company-oriented ones were found, implying that employers on the whole were not interested in constructing ideal images or subject positions for the targeted readers to take on, based on most of the samples derived from 2003. In other words, job advertisements in Taiwanese newspapers, also considered as a promotional discourse, were limited to the promotion of corporate images.

In light of RQ1, it is clear that fewer and fewer companies relied on print advertisements to attract potential applicants from the labor market, and that the significance of newspaper job advertisements as a recruiting discourse was becoming weaker over the 20 -year period in question. This is readily explicable when one takes into account the increasing use of company websites to construct corporate images as well as to enable mutual or interactive communication between companies and potential job applicants (Chapman \& Webster, 2003).

Due to the space limitations of this paper, some additional dimensions of the multimodal choices involved in the design of job advertisements have been overlooked, and could represent fruitful directions for future research. For example, content analysis is capable only of revealing visual communication patterns as realized in the frequency of pre-determined coding dimensions: it cannot reveal implied, connotative meanings conveyed via the choices of various visual semiotic resources, such as the symbolic meanings of icons, lexical and visual interactions for meaning-making, distance, gazes, poses, the angles viewers take in relation to represented people in pictures, or the visual positioning of individuals in pictures as models for targeted job applicants to identify with. A qualitative multimodal analysis could provide a range of additional insights into the putative relationships between employers and potential employees that are visually constructed in job advertisements. It would also be worth exploring recruiting websites' strategies and techniques for attracting candidates, as compared to those of traditional job advertisements printed in newspapers.

\section{References}

Allen, D. G., Mahto, R. V., \& Otondo, R. F. (2007). Web-based recruitment: Effects of information, organizational brand, and attitudes toward a Web site on applicant attraction. Journal of Applied Psychology, 92(6), 1696-1708.

Belt, J., \& Paolillo, J. (1982). The influence of corporate image and specificity of candidate qualifications on response to recruitment advertisement. Journal of Management, 8(1), 105-112. 
Berelson, B. (1952). Content analysis in communication research. New York: Free Press.

Blackman, A. (2006). Graduating students' responses to recruitment advertisements. Journal of Business Communication, 43(4), 367-388.

Breaugh, J. A., \& Starke, M. (2000). Research on employee recruitment: So many studies, so many remaining questions. Journal of Management, 26(3), 405-434.

Chang, Y. H., \& Fu, Y. C. (2003). Taiwan social change survey (Round 4, Year 4) (NNSC 92-2420-H-001-002-B1). Taipei: Ministry of Science and Technology.

Chapman, D. S., \& Webster, J. (2003). The use of technologies in the recruiting, screening, and selection processes for job candidates. International Journal of Selection and Assessment, 11(2-3), 113-120.

Cook, K. P. (2002). Recruiting new faculty? Change your rhetorical perspective. Proceedings of 29th Annual Conference Council for Programs in Technical and Scientific Communication (pp. 119-122). Logan, Uta.

Davids, M. (1986). How to plan and place corporate advertising in print media. Public Relations Journal, 42, 29-30.

Fairclough, N. (2001). Language and power. New York: Longman.

Fyock, C. (1988). New ways to say "help wanted". Personnel Administrator, 33, 101-109.

Greenberg, E. (1986). The costs and strategies of recruitment advertising. Compensation and Benefits Review, 16, 69-73.

Holsti, O. R. (1969). Content analysis for the social sciences and humanities. Reading, MA: Addison-Wesley.

Huang, C. I., Chang, K. I., \& Du, P. L. (2002). The content and appeal of recruitment advertisements in newspapers: Sponsor versus job seeker. Journal of Human Resource Management, 2(2), 99-112.

Kaplan, A. B., Aamodt, M. G., \& Wilk, D. (1991). The relationship between advertisement variables and applicant responses to newspaper recruitment advertisements. Journal of Business and Psychology, 5, 383-391.

Kress, G., \& Van Leeuwen, T. (2006). Reading images: The grammar of visual design. New York: Routledge.

Krippendorff, K. (2004). Content analysis: An introduction to its methodology. Thousand Oaks, CA: Sage.

Lester, P. (2014). Visual communication: Images with messages. Boston, M.A.: Wadsworth.

Magnus, M. (1986). Recruitment advantages. Personnel Journal, 65, 58-77.

Martin, B. (1987). Recruitment ad ventures. Personnel Journal, 66, 46-63.

Mathews, B. P., \& Redman, T. (1998). Managerial recruitment advertisements-just how market orientated are they? International Journal of Selection and Assessment, 6(4), 240-248.

Rai, H., \& Kothari, J. (2008). Recruitment advertising and corporate image: Interface between marketing and human resources. South Asian Journal of Management, 15(2), 47-60.

Rawlinson, H. (1988). What do your classified ads say about you? Recruitment Today, 1, 47-52.

Roberson, Q. M., Collins, C. J., \& Oreg, S. (2005). The effects of recruitment message specificity on applicant attraction to organizations. Journal of Business and Psychology, 19(3), 319-339.

Ryan, G., Gubern, M., \& Rodriguez, I. (2000). Recruitment advertising: The marketing-human resource interface. International Advances in Economic Research, 6(2), 354-364.

Stoops, R. (1984). Recruitment ads that get results. Personnel Journal, 63, 24-26.

Titscher, S., Meyer, M., Wodak, R., \& Vetter, E. (2000). Methods of text and discourse analysis. London: Sage. 